\title{
THE COPULATORY BEHAVIOUR OF ADULT MALE PATAS MONKEYS, ERYTHROCEBUS PATAS
}

\author{
JAMES LOY \\ Department of Sociology and Anthropology, University of Rhode Island, \\ Kingston, Rhode Island 02881, U.S.A.
}

(Received 22nd February 1975)

The present observations of the reproductive behaviour of adult male patas monkeys (Erythrocebus patas) suggest that these primates typically copulate during a single mount unless they experience difficulty achieving intromission and/or they are harassed by conspecifics. These observations are in contrast to the report by Hall et al. (1965), who described a patas male who copulated in a series of mounts, i.e. behaviour similar to that of males of several macaque species (Bielert \& Goy, 1973; Nadler \& Rosenblum, 1973).

The patas monkey group observed during the present study was maintained in a $\frac{1}{2}$ acre outdoor corral at the primate colony at La Parguera, Puerto Rico, a facility of the Caribbean Primate Research Center. The monkeys were provided with an unlimited supply of Wayne Monkey Diet and water. Behavioural observations were made from November 1971 until June 1974 for a total of $781 \mathrm{hr}$.

The original social group consisted of a single adult male (A), eight adult females, two immature males and two immature females. All of the monkeys were thought to be of East African origin. During the spring of 1972, Male A was replaced by adult Male L173; this switch was necessitated because of repeated attacks on the colony staff by Male A. The birthplace of Male L173 was not known.

In addition to the copulatory behaviour of Males L173 and A, some data from adult Male I are included. Male I was released to be free-ranging at La Parguera with a small group of females in the autumn of 1972. Notes on the behaviour of Male I were made when the free-ranging patas came near the study corral.

Patas monkey females exhibit oestrus in distinct periods which average $12 \cdot 0$ days in duration (range 1 to 66 days) and which occur cyclically at intervals averaging 31.9 days in length (range 10 to 78 days) (J. Loy, unpublished data). Oestrus is indicated by the female actively seeking the attentions of the adult male, primarily through the use of a display known as sexual soliciting (Hall et al., 1965).

Mounts and copulations (as defined below) by the adult male are closely correlated with the female oestrous periods. These periods of sexual receptivity were identified and measured by the occurrence of the soliciting pattern. During this study, 87 mounts by the adult males on adult females were seen 
in the corral, including 21 copulations. Ninety-eight per cent of the mounts and $100 \%$ of the copulations occurred during oestrous periods.

The mounting posture of the adult male patas has been described by Hall, et al. (1965). Generally, the male positions himself behind the crouching female, grasps her lower sides with his hands, and flexes his legs to facilitate intromission. The male may occasionally obtain a single or double foot-grasp on the legs of the female. A mount may or may not include pelvic thrusts and intromission; likewise, a mount with intromitted pelvic thrusting may or may not culminate in ejaculation. When ejaculation does occur, it is recognized by the several rapid, intromitted pelvic thrusts followed by a few seconds of immobility and body tenseness by the male. In this study, a single mount with ejaculation was termed a single-mount copulation. If a patas male is unable to complete the first mount, he may have to mount the female a second or third time before reaching the ejaculation threshold; matings of this type were termed multiple-mount copulations.

Eighteen of the 21 observed complete copulations were executed by Male L173, two by Male A, and one by Male I. The single-mount copulatory pattern was the modal variety (fourteen instances), but some multiple-mount copulations were also observed. The mean number of mounts/copulation was 1.6 (range 1 to 4 ).

Six of the seven multiple-mount copulations were explicable deviations from the single-mount pattern following the theory that more than one mount was required only if the first mount was not sufficient to arouse the male to ejaculation threshold. (1) In four of the multiple-mount copulations, the male failed to achieve intromission on all mounts before the ejaculatory mount. Among the apparent causes for this failure was imperfect male-female posturing during the mount. (2) In two of the multiple-mount copulations, Male L173 achieved intromission on all mounts, but had all mounts except the final (ejaculatory) mount terminated prematurely by harassment from a juvenile male. Patterns of harassment included grabbing, slapping and charging-into the adult male while the latter was mounted. (3) The seventh multiple-mount copulation (two mounts) may also have been due to conspecific harassment, but this was uncertain.

These observations thus suggest that patas males typically reach the ejaculation threshold during their first mount of an oestrous female. The multiplemount copulations observed at La Parguera appeared to have been series of copulation attempts ending finally in successful intromission and ejaculation, rather than true series-mount matings.

Twenty-four ejaculatory mounts by patas males were seen during this study; i.e. the twenty-one complete copulations, plus three additional instances in which the ejaculatory mount was seen, but there was some doubt that the entire mating had been witnessed. The number of intromitted pelvic thrusts was counted on 22 of these ejaculatory mounts, and the mean number was found to be $9 \cdot 6$ thrusts (range 4 to 15). The mean time for a patas ejaculatory mount (which appeared to be equivalent to the basic copulatory pattern for our males) was $12 \cdot 1 \mathrm{sec}$ (range 8 to $20 \mathrm{sec}$ ).

The observations of the LaParguera patas monkeys suggest that the single- 
mount copulatory pattern is typical for the species. This is in contrast to the report of Hall et al. (1965), who stated that their only patas male typically exhibited series-mount copulations; the implication being that the male was progressively aroused with each mount. Such a pattern is common for some macaques, e.g. the rhesus monkey, in which numerous mounts, and the social interactions which occur between mounts, are necessary to increase sexual arousal until the ejaculation threshold is attained (Missakian et al., 1969). Clearly, neither the study of Hall et al. (1965) nor the present one can be regarded as definitive, since too few males were sampled in both investigations. However, additional support for the conclusion that patas monkeys are singlemount copulators comes from the work of Dr Thelma Rowell who has indicated (personal communication) that captive West African patas are "also single mounters unless disturbed"'.

The behaviour of Hall's adult male remains problematical, but one possible explanation for that male's multiple-mount copulations is that he was under stress during interactions with oestrous females. Hall himself noted that the male and his partner were frequently harassed by other monkeys during their copulation attempts (Hall, 1967). The present paper has indicated that harassment can transform a single-mount copulation into a multiple-mount pattern.

Further research into the reproductive patterns of the patas monkey is needed. At the present time, however, the weight of the available evidence suggests that the single-mount copulatory pattern is characteristic of patas monkeys.

The Caribbean Primate Research Center is supported by contract NIHDRR-71-2003 from the Division of Research Resources, NIH. I thank Dr G. H. Conaway, Dr R. W. Goy, Dr T. E. Rowell, and Mrs Kent M. Loy for their assistance with the study and/or the manuscript.

\section{REFERENGES}

Bielert, C.F. \& Goy, R.W. (1973) Sexual behavior of male rhesus: effects of repeated ejaculation and partner's cycle stage. Horm. \& Behav. 4, 109-122.

HaLL, K.R.L. (1967) Social interactions of the adult male and adult females of a patas monkey group. In Social Communication Among Primates, pp. 261-280. Ed. S. A. Altmann. University of Chicago Press, Chicago.

Hall, K.R.L., Boelkins, R.G. \& Gosweld, M.J. (1965) Behaviour of patas monkeys, Erythrocebus patas, in captivity, with notes on the natural habitat. Folia primat. 3, 22-49.

Missakian, E.A., Del Rio, L.R. \& MYers, R.E. (1969) Reproductive behavior of captive male rhesus monkeys (Macaca mulatta). Commun. behav. Biol. 4, 231-235.

NAdLeR, R.D. \& Rosenblum, L.A. (1973) Sexual behavior of male pigtail macaques in the laboratory. Brain, Behav. E̊ Evol. 7, 18-33. 